\title{
M-Theory of Communication: Search for Superstructure and Substructure Nature of Communication Including Models
}

\section{Achyut Aryal*}

Mewar University (MU), Gangrar, Chittorgarh, Rajasthan, India

\begin{abstract}
This commentary article is an introduction about M-Theory of communication, its background, nature, process, elements and models which introduce superstructure and substructure of communication including some of its models. Furthermore it asks for further depth research in the field with experimentation. It constructs the claim communication as a multidimensional interaction from within as well as except communication discipline and its elements, which makes communication an existential process since 3,000 years and more.
\end{abstract}

Keywords: M-Theory; Communication; Models; Superstructure; Substructure

\section{Overview}

As a concept following Stephen Hawking's term 'M-Theory' a media scholar in east contributed a unified theory in communication, including mass communication and its process. That was happened in 2009 through a book, namely 'Labor-Interactional Grand-Network and The Dictatorship of The Perfect Proletariat' (Nepali:Shram antarkriyatmak Mahasanjaal Ra Purnasarbahaara Adhinaayaktto, ISBN: 978-9937-22196-2). A full chapter 'Labor Interactional Grand-Network' of the book (Pg. 19-36) conceptualizes the nature of 'Meta Theory' (M-Theory) in communication including 'Labor Interactional Grand-Network Model of Communication', 'Superstructure of Communication' and 'SubStructure of Communication'. Those concepts were very unique and firstly explained by a scholar in communication and media field: The LIGN model has been presented through different other efforts by myself. The LIGN model of Communication was presented and discussed in various programs (for e.g., organized by Journalism Study Center(CSC) in 2010, January 12; Nepal Management and Sciences (NIMS) College, Mass Communicatione Journalism Department in 2011, Feb. 12; and by Nepal-Korea International College(NKIC), Biblical Communication and Communication Department in 2012, January 10 [1] .

Second attempt was made and this concept had been presented in Third Media research Conference 2012, entitled 'State Before and After Communication Process: A Conceptual Study of Meta Theory (M-Theory) of Communication, organized by Martin Chautari and Department of Language and mass Communication, Kathmandu University jointly. Then the revised version after huge criticism on it by scholars in the field came as construct.

\section{M-Theory: Communication}

For the search of M-Theory as a complete theory of the universe in communication and media field concept and the theoretical framework are constructed with: Communicationis a labor where multidimensional interaction is going on from within communication discipline and its elements; and from except communication field which makes communication a process. Feedback only doesn't make communication a process. When labor interaction gets weak then communication process goes to an end. It applies on both communication process and on individual labor unit of communication process (sender, receiver, message, channel, encoding, decoding, noise, context, Feedback etc.) [2].

In case of M-Theory in communication field paper is clear and fixed, it spells: This research explores after communication process communication parties goes to beyond, and it is called here beyond-labor of communication. But happens rarely and only with few cases. Moksha, Nibbana, Arhat and many more terms has been used to represent this stage. So, this research represents science, aesthetic philosophies and non-labor (vast realities) in a single theory. And it is M-Theory of communication [3].

After review and a long commentary of previous works on communication theory field researcher arrives in aunique conclusion of M-Theory of communication (Figure 1).

\section{Models under M-theory}

There are so many models with explanation of all communication parties including- sender or source, receiver, feedback, channel, message, noise, encoding, decoding, context etc. All has a unique connection as well as a nature to come from somewhere, interact until having interaction capacity and again return back from where it had been. It is happening with individual elements as well as with whole process. No researcher ever has given such sight, even in communication model. After some evidences and proof research paper arrives to a unique conclusion with various models, some of them are:

- Labor-Interactional Grand-Network Model of Communication

-Super-Structure of Communication

-Sub-Structure of Communication

- Multidimensional complexity of Communication's interaction (Figure 2)

The model of M-Theory as 'Labor-Interaction Grand-Network' is:

'Labor-Interactional Grand-Network of Communication' sought to study all types of communication and even more; verbal and non-verbal

${ }^{*}$ Corresponding author: Achyut Aryal, Mewar University (MU), Gangrar Chittorgarh, Rajasthan, India, Tel: 977-9741060086; E-mail: aryala4dk@yahoo.com

Received September 19, 2013; Accepted November 12, 2013; Published November 19, 2013

Citation: Aryal A (2013) M-Theory of Communication: Search for Superstructure and Substructure Nature of Communication Including Models. J Mass Communicat Journalism 3: 165. doi:10.4172/2165-7912.1000165

Copyright: (c) 2013 Aryal A. This is an open-access article distributed under the terms of the Creative Commons Attribution License, which permits unrestricted use, distribution, and reproduction in any medium, provided the original author and source are credited. 


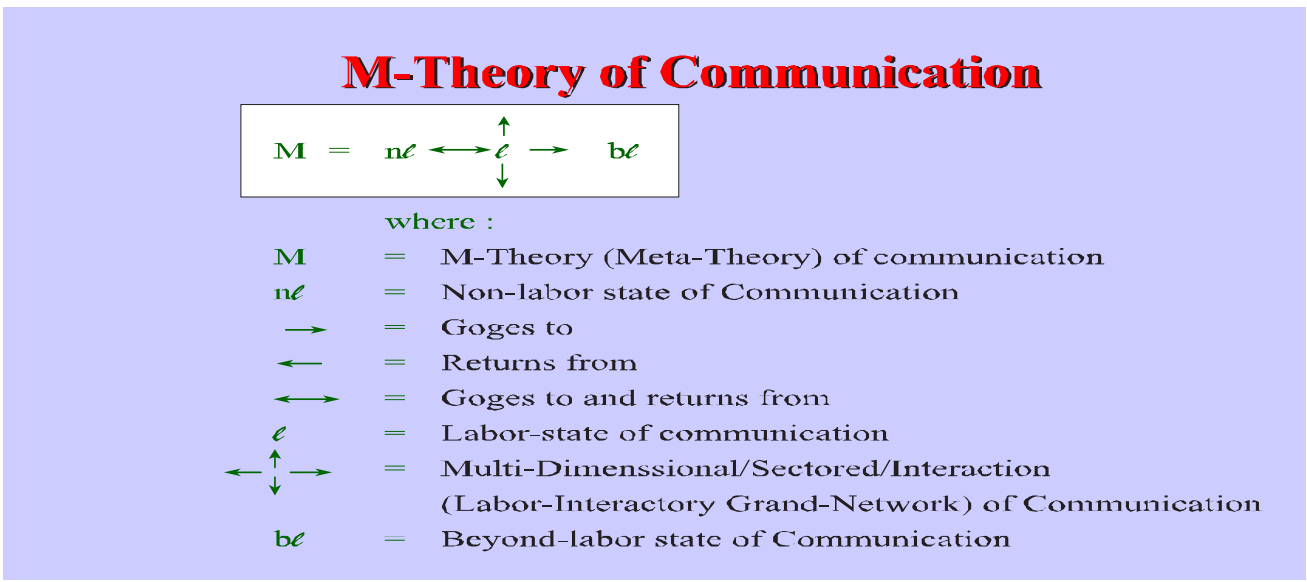

Figure 1: M-Theory of Communication in Figure.

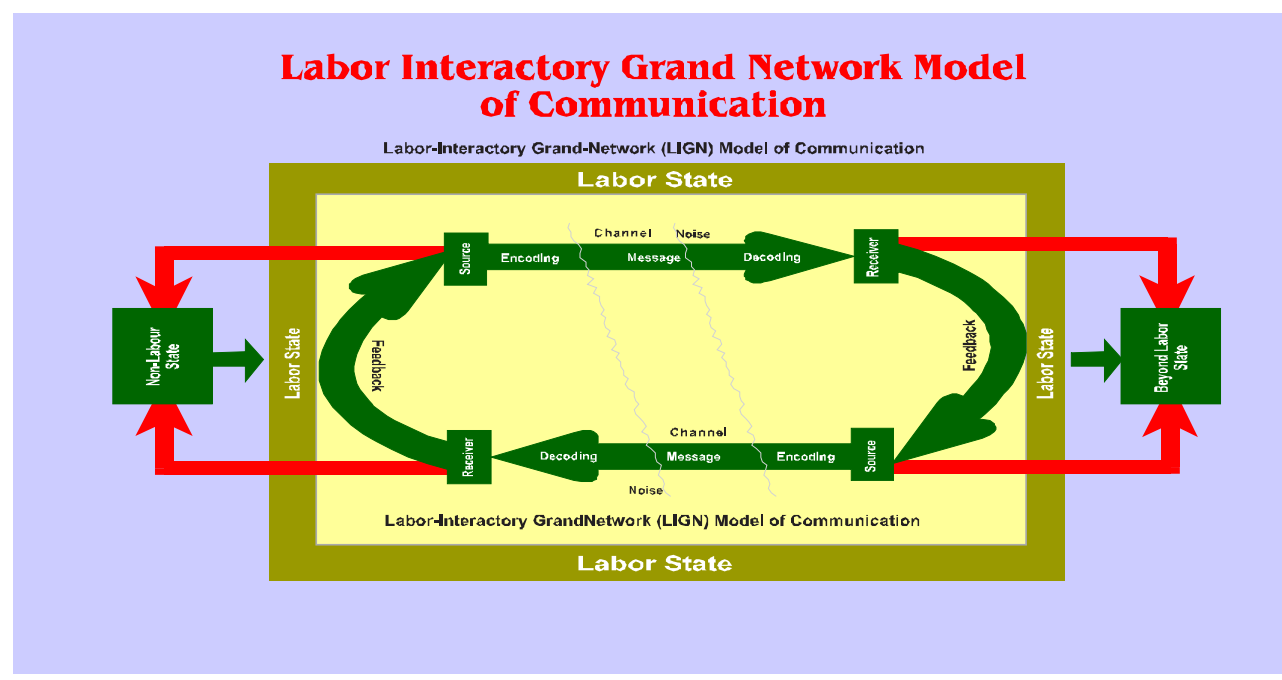

Figure 2: Model of Communication.

forms of communication, direct and mediated communication, fivelevels of communication(inter-personal communication, intra-personal communication, group-communication, organizational communication, mass communication) from communication as a labor point of view. Without grand-labor interaction (GLI) it is impossible for intra-personal communication to reach mass communication level. Labor-Interaction is only the factor behind it. It theorizes that every communication process remains between non-labor and beyond-labor. The communication process remains there as an active labor interaction with multidimensional labors of existence. Moreover, it does not limit only with labor; concept views that all the modern communication tools, techniques, ideas, concepts, visions, theories and models are developed thoroughly labor-interaction. And it continues further. Labor-interaction makes development automatically. In communication field too, same condition applies [4].

\section{Super structure}

Non-labor to labor and again back to non-labor from labor; except this, communication has some goals. As philosophical point of view there is another stage. Concept opined it as beyond-labor. It is neither labor nor non-labor. It is beyond. It is inexpressible. It cross all the limitations of labor-interaction and even in communication such stage is idol stage and ultimate goal of communication. It is 'Sramaatit' (enlightenment), neither 'sram' nor 'asram'. It is beyond labor of communication (BLC). It is ultimate achievement of communication labor. From here it's not necessary to return back again in labor and non-labor. It is complete and it is perfect. Mohamad, Jesus, Buddha, some Hindu Gurus and many others in the past history had attained such stage through labor-interactional grand-network (Figure 3).

In this way it can be said communication first of all remains in non-labor stage, somewhere in hidden and as passive form. It contains no movement and even no motion. It remains in complete inactive state. In appropriate condition with some catalytic notion non-labor condition of communication naturally enters in labor. This stage is philosophically very complex. Complexity arouses during vast and multi-dimensional labor-interaction between individual and collective labor forces. As a whole, communication labor runs until each and every labor unit remains in state of labor, actively. When one of many labor units fails to do labor in active way suddenly communication process of a context goes to an end. It means it returns in non-labor. Maximum communications labor (process) remains just between labor and nonlabor. Only the conscious and even super-conscious labor can enter in 


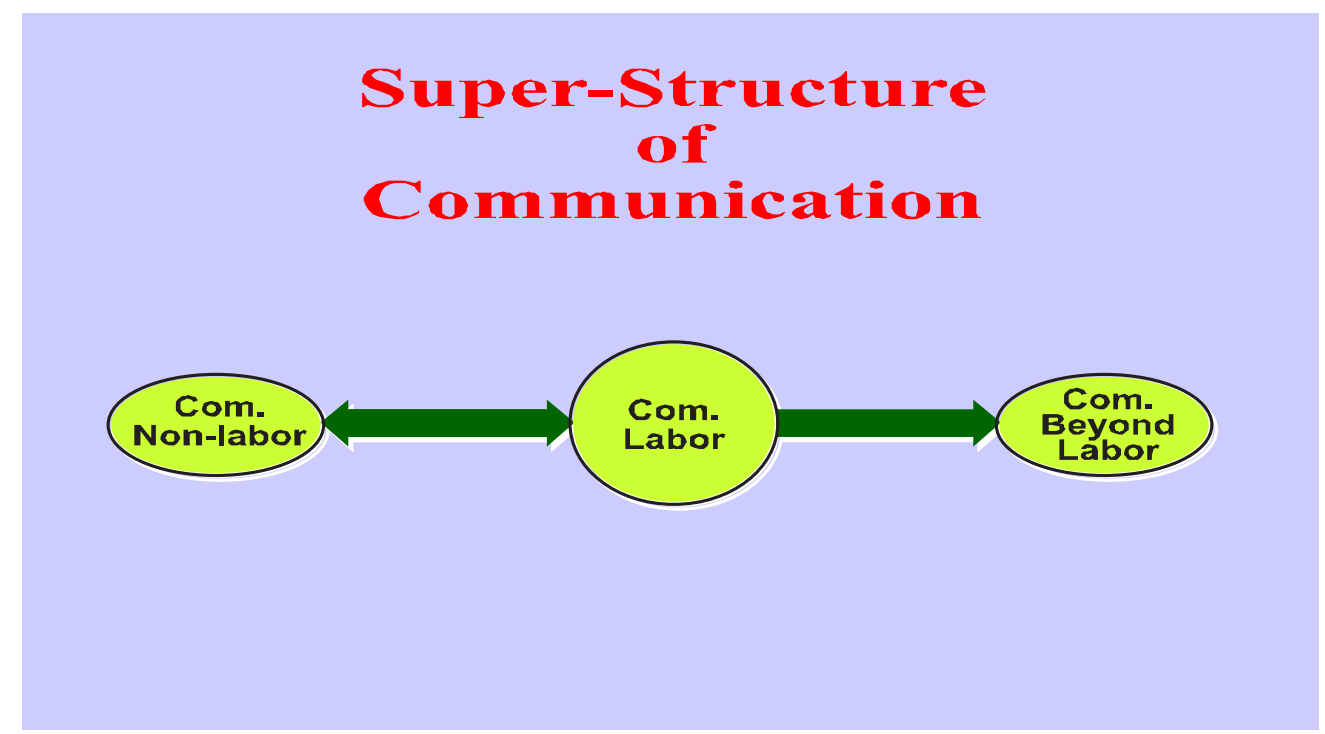

Figure 3: Superstructure of Communication.

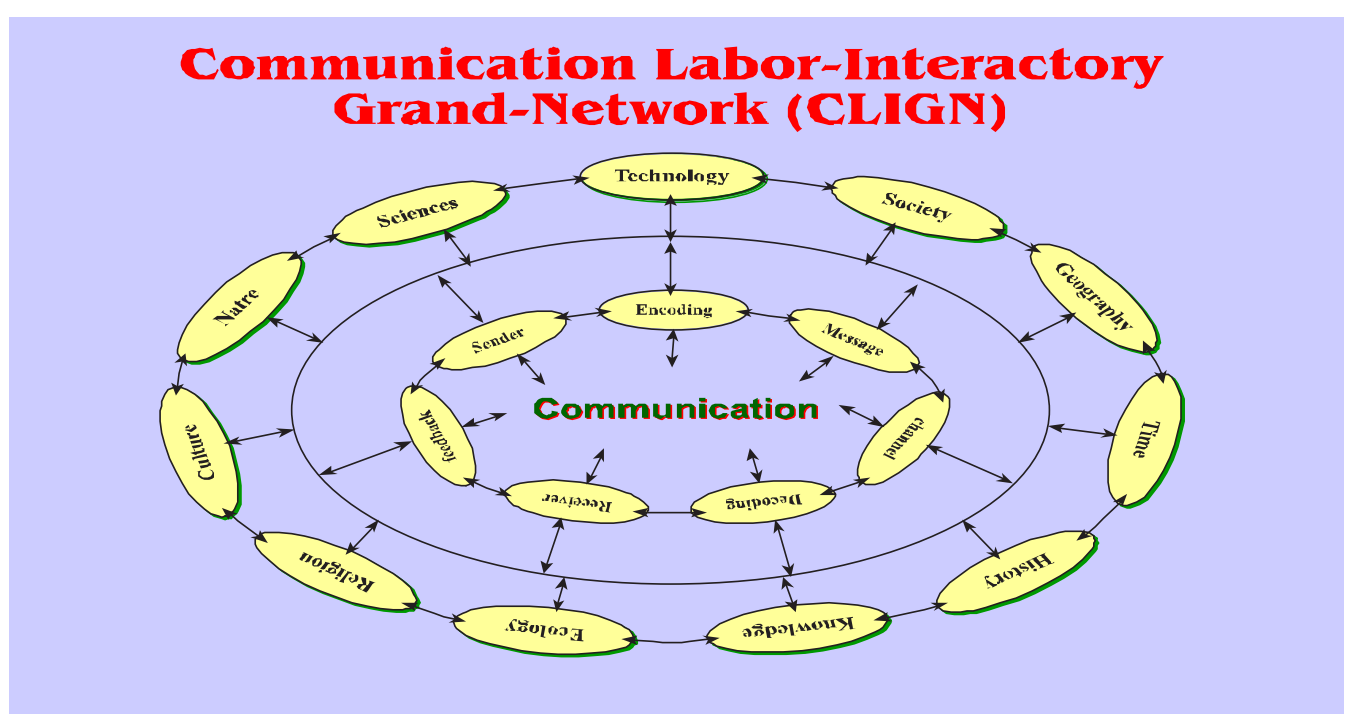

Figure 4: Multidimensional Complexity of Communication's Interaction.

beyond from communication. Only those who understand non-labor and labor in complete way and its complexity can easily enter on such stage by self-effort. Which we can say Moksha, Nibbana, Arhat, Jannat, Heaven etc [3].

\section{Sub structure}

Earlier, communication discipline had borrowed concepts and models from other disciplines of psychology, sociology, and anthropology etc. Multidimensionality of interaction and changes in communication discipline had been outlined this way (Figure 4).

What I have proposed so far is the outcome of my sincere attempt to understand the communication process. I am continuing my research in order to explore perspectives on communication from the standpoint of the complex labor-interactional grand-network understanding. Here, I am presenting the state before and after communication process in future to develop M-Theory of Communication with a hope to get scholarly feedback. Pursuit of knowledge is our common ground, and any endeavor of enriching the communication discipline certainly serves this [1].

The state before and after communication process conceptual study seems tohave proposed consisting of following stage as elements:

1. Non-labor (Passive condition of communication elements and process)

2. Labor (Active condition of all communication elements and process)

3. Beyond-labor (Neither active nor passive condition of communication elements and process, it is ignorance of both) 


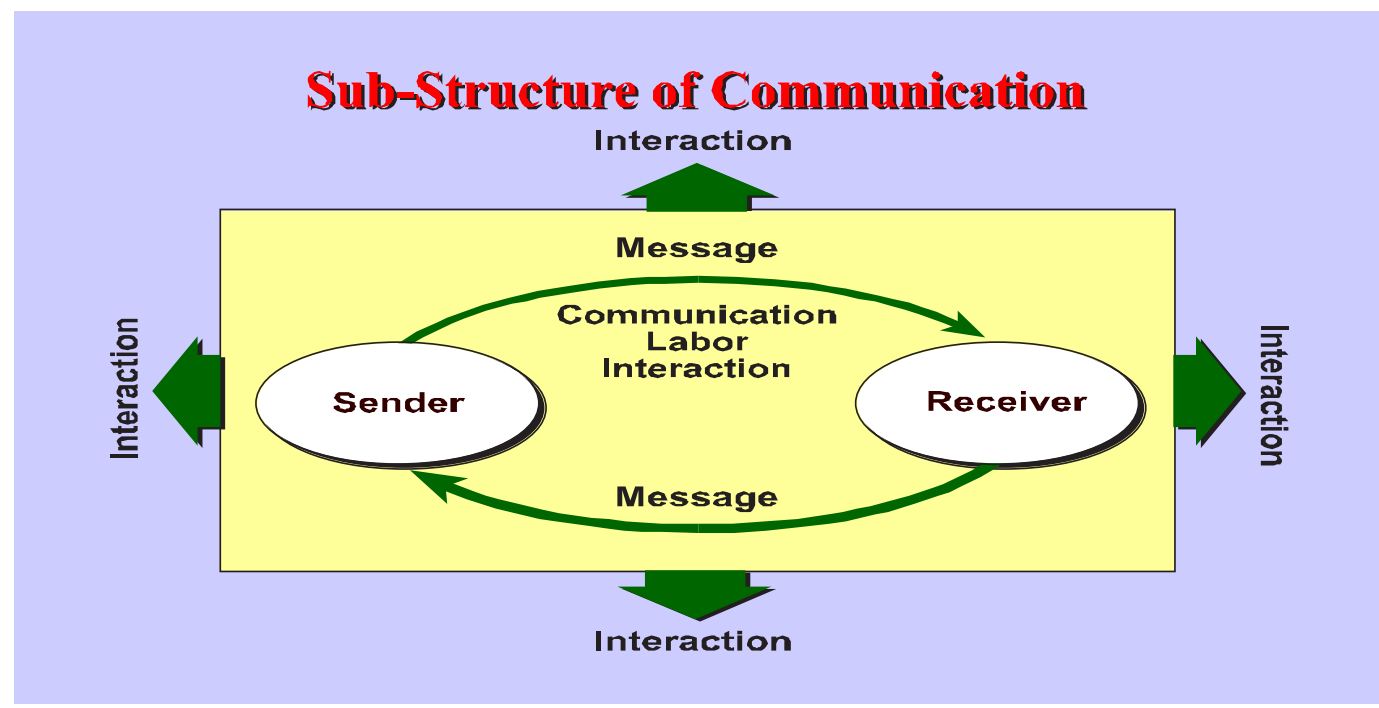

Figure 5: Substructure of Communication.

4. Labor-Interaction (Interaction between all labor units- sender, message, channel, receiver, feedback, noise, context, encoding, decoding etc.)

5. Multidimensional Interaction (It happens within and except communication field with multidimensionality); and it is called LaborinteractionalGrand-Network of communication (Figure 5).

\section{Conclusion}

Presenting a new theory on the basis of some concept is very difficult. It has been happening since Aristotelian tradition of the study of communication conceptualized in Rhetoric. But here my angle is completely new, different and unique from other. I am denying here any tradition. I am claiming that communication labor is happening with its own rule and system from the beginning and even before. It goes and returns within in the periphery of labor and non-labor. And by chance sometimes it goes for beyond too. This is complete theory, which can represent all existing, non-existing and more communication model, concept and theories within itself; that's why this concept can have capacity to become Meta Theory (M-Theory) in communication field. Non-labor, labor and beyond labor; and special connections between these three makes a complete theory and concept in every discipline.
For communication perspective too, it applies the same. I have given an equation, which is very first kind in communication discipline that such a simple equation can cover and take capacity to explain everything in communication.

Explanation is: non-labor (NL) state of communication goes to and/or returns from labor (L), where multidimensional (or sectored) interactions happens and in some cases(few cases) it goes to beyond labor.

\section{References}

1. Aryal A (2009) Labor- Interactional Grand Network \& the Dictatorship of perfect proletariat. Perfect Proletariat party (PPP), Kathmandu, Nepal.

2. Aryal A (2012a) State Before and After Communication Process: A Conceptual Study of Meta Theory (M-Theory) of Communication, Third Media Research Conference 2012 (best paper), organized by Martin Chautari and Department of Language and mass Communication, Kathmandu University,Dhulikhel, Nepal.

3. Aryal A (2012b) M-Theory of Communication and Scope; A Conference organized by Nepal Institute of Management and Sciences (NIMS), Lagankhel, Lalitpur, Nepal.

4. Aryal A(2012c) M-Theory of Communication: Biblical Perspective, A Conference organized by Nepal-Korea International College, Seoul Theological University, Hattiban, Lalitpur, Nepal. 